Fecha de recepción: febrero 2017 Fecha de aceptación: agosto 2017 Versión final: septiembre 2018

\section{Quando o design e a ressignificação de uma matéria prima modificam as vidas de uma comunidade: Estudo de caso do projeto Cooperárvore do Programa Ârvore da Vida da FIAT Automóveis}

Camilo de Lelis Belchior *

\begin{abstract}
Resumen: El presente artículo se refiere a un estudio de caso de una acción que está siendo desarrollada desde 2006, con resultado sorprendente. Entre una variedad enorme de tejidos automotores, restos de estructuras de la parte interna de los coches (como cinturones de seguridad, tirantes y etc.), además de una maquinaria diversificada, 22 cooperativas trabajan en Cooperárvore, una cooperativa creada por el Programa de Política de vinculación con la comunidad de FIAT. Este proyecto está situado en la ciudad de Betim (BH). En un gran galpón perteneciente a esta cooperativa, se crean y generan una variedad de productos surgidos de una materia prima innovadora y ecológicamente correcta: insumos y recortes resultantes de la producción interna de los vehículos producidos por FIAT Automóviles.
\end{abstract}

Palabras clave: diseño social - cooperativa - sostenibilidad - Responsabilidad social corporativa.

[Resúmenes en inglés y portugués en la página 219]

* Pesquisador e professor da Escola de Design da Universidade do Estado de Minas Gerais.

\title{
Introdução
}

Em pleno inicio do Século XXI presenciamos uma nítida mudança nas relações entre o homem e os objetos. O design está se tornando uma das disciplinas que mais contribui para o desenvolvimento de novos valores para os objetos como os que são intangíveis.

Estamos nos conscientizando dos limites de nosso planeta e da importância que ações sustentáveis emergenciais têm e as graves consequências caso as mesmas não sejam adotadas. Pensar neste cenário nos faz refletir a cerca da importância do design para este contexto uma vez que ele pode ser o mediador entre a humanidade, os artefatos e a nova consciência sustentável.

O filosofo John Thackara (2008), em seu livro Plano B faz uma reflexão importante para a atual condição mundial. Ele nos fala que muitas das situações preocupantes no mundo atual são resultado de decisões do design. Ele ainda nos alerta para a perigosa condição do planeta e afirma que grande parte das decisões que advêm do design moldam os proces- 
sos por trás dos produtos que utilizamos, os materiais e a energia gasta para produzi-los. Para o autor, oitenta por cento do impacto ambiental dos produtos no mundo, serviços e infraestrutura ao nosso redor são determinados pelo design. Uma das propostas do autor é fazer com que os processos e sistemas que nos cercam sejam mais inteligíveis e desvendáveis. Segundo Thackara, precisamos projetar de forma mais ponderada, ou seja, que os princípios da sustentabilidade sejam mais claros: eliminar o conceito de desperdício, reduzir o movimento e a distribuição dos bens, utilizar mais pessoas e menos matéria prima e contar com fluxos de energia natural. E da mesma forma que o autor acredita na responsabilidade causa do design, ele também acredita que o design pode e deve contribuir em processos produtivos mais inteligentes e criativos.

E pensando nesta colocação de John Thackara que o presente artigo se refere, fazendo um estudo de caso sobre uma ação que já está sendo desenvolvida desde 2006, com resultado surpreendente, mostrando como o ato de ressignificar um material pode resultar em ações fortemente positivas para uma comunidade e ainda ser sustentável.

Entre uma variedade enorme de tecidos automotivos, retalhos de estruturas da parte interna dos automóveis, como cintos de segurança, alças e etc, além de um maquinário diversificado, 22 (vinte e duas) cooperadas trabalham na Cooperárvore, uma cooperativa criada pelo Programa de Política de Relacionamento com a comunidade, chamada Árvore da Vida, criada pela montadora de automóveis FIAT. Este projeto está situado na cidade de Betim, região metropolitana de Belo Horizonte (capital de Minas Gerais/Brasil). Em um grande galpão pertencente a esta cooperativa, são criados e produzidos uma variedade de produtos oriundos de uma matéria prima inovadora e ecologicamente correta, trata-se de insumos e aparas resultantes da produção interna dos veículos produzidos pela FIAT Automóveis.

\section{Entendendo a ressignificação}

Em pleno início do século XXI é fato entendermos o design como um articulador importante no processo de desenvolvimento de artefatos, para consumo ou não. Olhando pelo aspecto do consumidor, evidenciamos uma velocidade grande na exigência de novos artefatos, imposta na maioria das vezes pelo próprio mercado. Neste momento a solução encontrada pelas empresas é a produção maciça e contínua de produtos que buscam encontrar sucesso de vendas. O resultado deste processo é o aumento exagerado na oferta de produtos que na maioria das vezes não acrescentam em nada na relação homem/objeto. Deyan Sudjic nos fala desta situação que vivemos:

Nunca possuímos tantas coisas como hoje, mesmo que as utilizamos cada vezes menos. As casas em que passamos tão pouco tempo são repletas de objetos. (...) São os nossos brinquedos: consolos às pressões incessantes por conseguir o dinheiro para comprá-los, e que, em nossa busca deles nos infantilizam. (Sudjic, 2010, p. 5)

O design, como articulador presente em boa parte deste processo, tem uma responsabilidade ímpar, com atuação no projeto de produto que envolve vários outros segmentos, 
como: tecnologias, ergonomia, estética, economia ambiental e social, aspectos antropológicos, entre outros. Esta ampla atuação aumenta ainda mais a responsabilidade do design, que neste caso passa a mediar todos estes aspectos no processo de produção de novos artefatos. Já sabemos que o design desempenha papel importante em todo ciclo de vida do produto, da sua concepção ao seu final de vida, compreendendo aqui nos dias atuais sua reciclagem ou descarte consciente. Porém, devemos entender que nem todo produto hoje chega ao seu desuso no final de sua vida útil. A nova ordem do cosumo dita novas regras: comprar, ter, possuir, descartar! John Thackara nos fala:

As decisões de design moldam os processos por trás dos produtos que utilizamos os materiais e energia necessária para produzi-los, o modo como o operamos no dia-a-dia e o que acontece com eles quando perdem a utilidade. Podemos não ter previsto tudo isso e podemos lastimar pelo que aconteceu, mas as situações que enfrentamos hoje foram de uma forma ou de outra planejadas por nós no passado. (Thackara, 2008, p. 24)

A proposta do autor é muito simples: "se pudemos planejar como entrar em uma dificuldade, podemos planejar como sair dela" (Thackara, 2008, p. 26). O autor acredita que os designers estão passando por um processo de evolução que vai de autores individuais de objetos a facilitadores na mudança de pensamento entre grandes grupos de pessoas e para acontecer isto, a proposta do autor é: "para mudar a forma como fazemos as coisas, precisamos mudar a forma como as percebemos" (Thackara, 2008, p. 18). E é a percepção o elemento principal para entendermos como ocorre o processo de ressignificação, que num primeiro estágio se relaciona diretamente como a forma pela qual percebemos os objetos a nossa volta, aliás, não só os objetos, mas todo o espaço que nos circundam e a partir deste momento vamos criando seus significados.

Os significados são inerentemente inconclusos. O significado mantémse como uma realização temporária, sujeito a acréscimos e alterações por meio de significações suplementares. O que é fixado e estabelecido em um momento pode tornar-se ambíguo e ser desfeito no próximo. Podem ocorrer negações e alterações dos intercâmbios como formas de atividade significativa. Essas mudanças estão sujeitas a ocorrerem continuamente por meio da interação com e entre os outros (tais como amigos, parentes, terapeutas e mídia). (Grandesso, 2000, p. 168)

De acordo com as necessidades humanas, o homem e a sociedade criam categorias de significados para os objetos que podem ser caracterizados em infinitas possibilidades, como: objetos religiosos, comerciais, domésticos, artísticos, exóticos, entre outros. Eles ainda podem apresentar a historicidade de cada usuário, que evolve lembranças, saudades, subterfúgios e vários outros tipos de sentimentos que acompanham o indivíduo por toda a sua vida. Estes objetos são capazes de armazenar uma serie de significações que fazem alusão a modelos e estilos da vida humana em uma determinada cultura. Através de fatores como cores, materiais, texturas, entre outros é possível aos designers à construção de referencias 
da temporalidade destes objetos. Sobre esta relação temporal, Baudrillard (2006) nos esclarece que não se trata do tempo real, porque na verdade os objetos são signos ou indícios culturais do fator tempo e estes fatores estão também diretamente relacionados à percepção que criamos sobre estes objetos.

A percepção, que é o conjunto de nossos sentidos (visão, olfato, paladar, tato e audição) que determina como entendemos o ambiente externo a nós. É a partir dela que nosso corpo e mente estabelece vínculos com outras pessoas, com os objetos e com tudo que existe ao nosso redor, o que permite uma infinita troca de informações entre estes elementos. Fica fácil entendermos esta relação com a afirmação de Cardoso (1998, p. 33) "os objetos só podem adquirir significados a partir da intencionalidade humana" e isto nos leva a compreender que uma das principais funções do design do século XXI é estabelecer uma linguagem/comunicação/relação entre os artefatos e o ser humano. Fica claro que o entendimento do design se origina na coletividade, que fornece a base de sustentação dos vários processos imaginários que compõe a linguagem expressa. Dentro deste contexto o profissional designer atua como identificador dos desejos e vontades coletivas, decodificando o que as pessoas querem ter, ser ou se expressar. O resultado desta interpretação leva este profissional a criar ou recriar novas linguagens de significados nos fazendo entender que a subjetividade se apresenta na caracterização do design, como nos fala Cardoso (1998, p. 33). Partindo deste pressuposto entendemos que o design tem em seu DNA a possibilidade de propor a ressignificação de elementos, valores, símbolos, atributos ou uso às coisas que compõe o nosso universo. Então ressignificar é propor um novo sentido ao objeto, alterando a forma como percepcionamos e conceituamos este objeto, o que o torna coerente sob um novo ponto de vista vigente.

Esta ressignificação precisa ser coerente com o desejo das pessoas, ou seja, o novo sentido que se propõe a um objeto existente precisa estar em consonância com o que as pessoas estão buscando naquele momento. Momento este que pode variar de acordo com uma série de aspectos temporais, específicos do contexto que se vive.

No livro, Design para um mundo complexo, Rafael Cardoso faz uma indagação interessante: "Ė possível que os conceitos encontrem expressão material: ou seja, que possam ser percebidos pelos sentidos físicos, como visão, audição, tato?” E nos responde dizendo:

Temos o costume de dizer que uma roupa é elegante, que um carro é luxuoso, que um prédio é imponente. Neste exemplos, estamos claramente atribuindo valores conceituais ao objeto a partir da associação com seus usos e usuários ou a partir da associação com outros artefatos da mesma categoria. (Cardoso, 2013, p. 28)

Para entendermos melhor a ressignificação atribuída a materiais, que é a fonte do nosso estudo de caso, apresentamos o exemplo do papelão. Na nossa sociedade, desde o seu surgimento, o papelão sempre foi percebido como um material de pouco valor agregado, descartável e até mesmo marginal, usado, na maioria das vezes, na confecção de embalagens. Este exemplo é de uma empresa paulista chamada Cartone que tem como função principal a criação e desenvolvimento de móveis e objetos produzidos única e exclusivamente com a matéria prima papelão. Aqui podemos perceber que houve uma ressignifi- 
cação do material, ou seja, aquele material que antes era percebido de uma forma pouco significante, aqui passa a ser percepcionado com outro significado, bem mais positivo que antes e principalmente com um valor agregado superior. (Ver Figura 1)

Outro exemplo a ser citado é o da ressignificação de outro material entendido na nossa sociedade, até então, como um material marginal, trata-se do compensado. Apesar de suas variadas qualidades, na nossa cultura o compensado ainda é um material que está sempre escondido atrás de lâminas de fórmica, melamínico, pintura ou mesmo como fundo de armários ou como base e forro de móveis. Sabendo desta situação, o autor deste artigo, que também é designer, desenvolveu com a participação de uma movelaria mineira, uma linha móveis utilizando apenas o compensado a vista. O Intuito desta ação foi o de demonstrar que aplicando a ressignificação através de técnicas do design o material poderia ser percepcionado de outra forma sem seus preceitos anteriores que o marginalizava. (Ver Figura 2)

Para validar a proposta do projeto, uma pesquisa quantitativa foi realizada e dentre os vários resultados obtidos por esta pesquisa, pode ser destacado: $86,5 \%$ dos entrevistados identificaram o material dos móveis como madeira maciça, 74,8\% disse que colocaria uma destas peças em posição de destaque em suas salas de estar. (Belchior, 2011, p. 151) Entendemos na nossa sociedade que a maior parte da variedade de madeiras maciças são muito valorizadas, reconhecidas como madeira de lei. Apenas com estes dois indicativos estatísticos já é possível comprovar que houve uma ressignificação do material compensado, alterando de forma significativa a sua percepção pelas pessoas.

De acordo com as nossas necessidades, criamos categorias de significados para os objetos que nos rodeiam, independentemente do lugar que eles ocupam em nossas vidas e com isto se apresenta toda nossa historicidade, que envolve nossas lembranças e outros sentimentos que fazem parte do nosso repertório de vida. Neste contexto, vale a pena ressaltar uma citação de Rafael Cardoso:

Quando se compreende a lógica segunda a qual as formas são constituídas, compreende-se também que elas são passíveis de mudança e de adquirirem novos significados. (....) As formas dos artefatos não possuem um significado fixo, mas antes são expressivas de um processo de significação - ou seja, a troca entre aquilo que está embutido em sua materialidade e aquilo que pode ser depreendido delas por nossa experiência. Por um lado, as formas concretizam os conceitos por trás de sua criação. (Cardoso, 2013, p. 35 e 36$)$.

Pensar na alteração radical dos significados contribui expressivamente para solucionar questões importantes para a humanidade e que são completamente estratégicas para empresas ou instituições, como nos afirma Roberto Verganti:

(...) executivos podem criar e implementar estratégias de inovação que geram produtos e serviços com significados completamente novos. Esses novos significados tornam-se a razão pela qual esses produtos e serviços são consumidos. Significados tão diferentes de tudo o que está no merca- 
do, que chegam a surpreender. Propostas tão diferentes, que acabam por converter as pessoas fazendo com que se apaixonem por estes novos significados. Verganti (2012, pag. 1 Carta ao Leitor).

Neste contexto existe uma serie de iniciativas de empresas e instituições que buscam encontrar formas criativas, inovadoras e estratégicas de resolverem uma questão socioambiental e ao mesmo tempo propiciar resultados surpreendentes, é o que veremos a seguir.

\section{O Programa Árvore da Vida}

Este programa é reconhecido como uma Política de Relacionamento entre a FIAT Automóveis e a comunidade local. O intuito do projeto é desenvolver as condições sociais da comunidade no entorno da fábrica de automóveis e foi dividido em 04 grandes ações:

1. Árvore da Vida / Capacitação - Oferece formação técnica na área automotiva para jovens com idade entre 18 a 24 anos, que estão em situação de vulnerabilidade social. $\mathrm{O}$ interessante aqui é que ao final da capacitação os alunos tem a possibilidade de serem contratados pela empresa.

2. Árvore da Vida / Voluntariado - Estimulo a participação cidadã na formulação e controle das políticas públicas, nos municípios onde a empresa está presente.

3. Árvore da Vida / Parcerias - Busca de empresas que tenham o mesmo pensamento com o objetivo de unir forças para o desenvolvimento social local.

4. Árvore da Vida / Jardim Teresópolis - Melhoria das condições de vida da comunidade que concentra cerca de 33 mil pessoas em três bairros vizinhos a fábrica da FIAT Automóveis.

O maior objetivo deste programa é a inclusão de crianças e jovens, por meio de ações socioeducativas, para possibilitar a geração de trabalho e renda aos moradores da região. Desde 2004, já foram beneficiados no programa mais de 20 mil moradores locais, cujos resultados são muito expressivos (fiat.com.br):

1. Em média, 23,3\% das famílias da região tem pelo menos um membro que participa ou já participou das atividades do Árvore da Vida;

2. Dos jovens participantes, $100 \%$ permaneceram na escola e $96 \%$ foram aprovados em 2013;

3. A população desempregada na comunidade caiu de $12,6 \%$, em 2004 , para $6,7 \%$ em 2013;

4. Aumento de $72,6 \%$ da renda das famílias da região de 2004 a 2013, sendo que a renda das famílias que possuem membros no programa é $25,7 \%$ superior em relação às famílias sem participação no programa. 


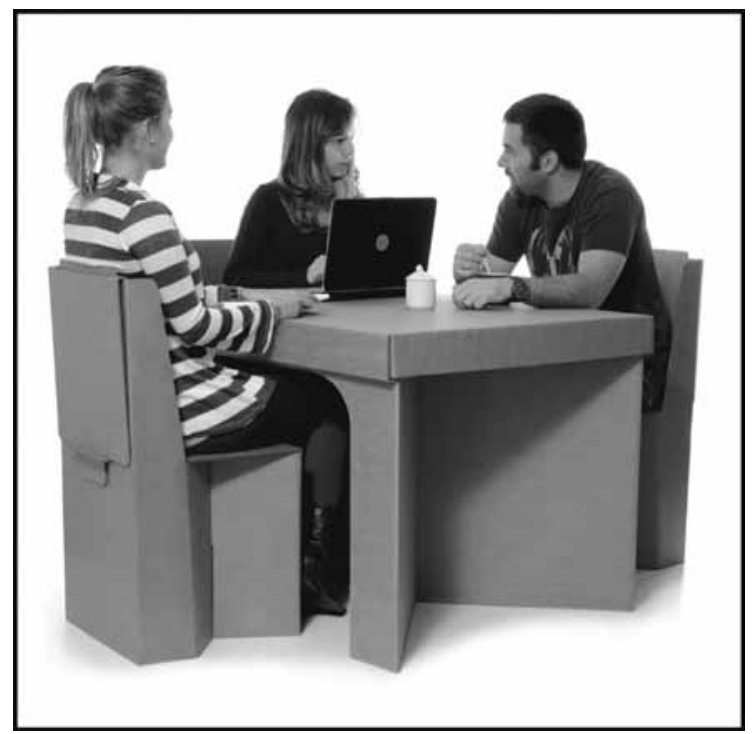

Figura 1.

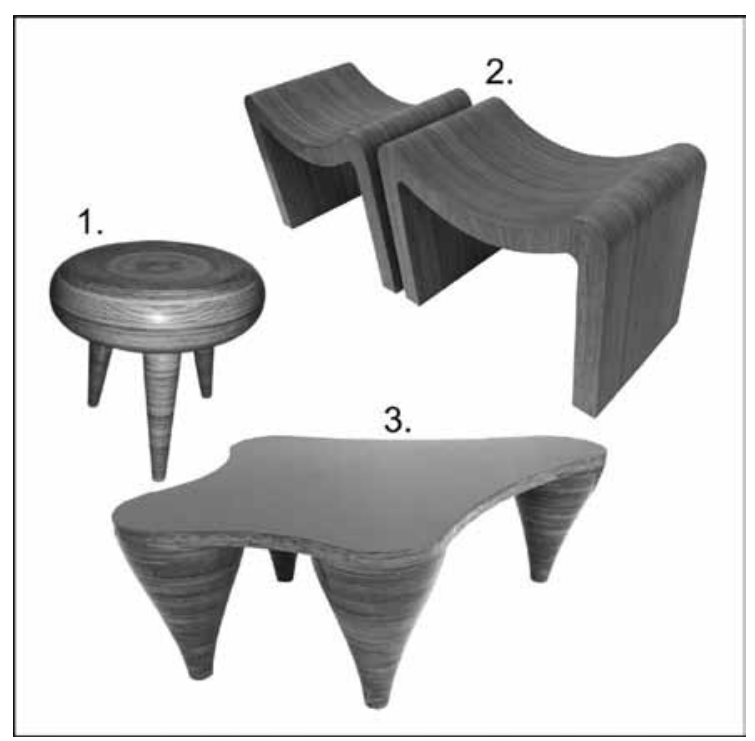

Figura 2.

Figura 1. Móveis de papelão produzidos pela empresa Cartone. http://cartonedesign.com.br Crédito da imagem: Divulgação. Figura 2. Móveis de compensado a vista. Criação: Camilo Belchior (2009). (1) Banco Pimá. (2) Banco Onda. (3) Mesa Sinuo. Fonte: do autor. 
O programa tem parceria com a ONG Cooperação para o Desenvolvimento e Moradia Humana (CDM) e a Fundação AVSI, além do suporte da Rede FIAT de Cidadania, que é constituída por uma aliança intersetorial gerida pela FIAT e formada por varias empresas, principalmente fornecedoras e concessionárias da FIAT, além do poder público e do terceiro setor, que se articula com foco no equilíbrio entre perspectivas econômicas, ambientais e sociais.

\section{O Case Cooperárvore}

A Cooperárvore é uma cooperativa social, baseada dentro do braço capacitação do Programa Árvore da Vida e tem por objetivo a produção de produtos confeccionados através de costura, silk e artesanato com materiais reutilizados vindos de aparas e sobras doados pela empresa FIAT Automóveis e sua rede de fornecedores. Esta cooperativa surgiu em 2006 e tem em sua composição mulheres que vivem no entorno da cidade Betim, que faz parte da região metropolitana de Belo Horizonte, capital de Minas Gerais/Brasil. O Principal objetivo da cooperativa é inserir as pessoas da comunidade em ações de geração de trabalho e renda. Esta cooperativa está inserida num programa maior chamado de Programa Árvore da Vida - Jardim Teresópolis.

Este programa foi vencedor agora em 2016 do "VI Prêmio Hugo Werneck de Sustentabilidade \& Amor a Natureza" na categoria Melhor empresa.

Em 2012 a cooperativa foi agraciada com o "Prêmio Economia Criativa" do Ministério da Cultura, e foi reconhecida como uma das 20 melhores iniciativas brasileiras no segmento. E em 2011, movida pelo sucesso de suas ações sociais, a Cooperárvore participou do "Encontro Para Amizade entre os Povos", em Rimini, na Itália, evento promovido pelo movimento eclesial Comunhão e Libertação, onde alguns integrantes da cooperativa tiveram a oportunidade de apresentar diversos produtos elaborados pelos cooperados e tiveram uma receptividade grande entre os participantes do evento.

Num galpão de grandes dimensões e entre tecidos automotivos, retalhos de cinto de segurança, algodão para assentos e muitas máquinas de costura trabalham cerca de 22 cooperadas confeccionando diversos produtos, que são criados e produzidos através de uma matéria prima já utilizada anteriormente na confecção de partes internas de um automóvel. Na linha de produtos existe: bolsas e carteiras femininas, malas, chaveiros, jogos, ecobags, produtos diversos para casa, brindes comerciais comprados geralmente por empresas, todos comercializados em feiras apropriadas, lojas de artigos similares ou pela internet através do site da cooperativa. Esta matéria prima já possui um significado para a sociedade de uma forma geral. Ao olhar para um tecido específico automotivo percebemos que se trata de algo elaborado para o assento ou forro de partes internas de um automóvel e assim acontece com as demais matérias primas.

Rafael Cardoso mais uma vez nos fala: “Os tempos mudam, e muda com eles o significado das coisas que parecem fixas" (Cardoso, 2013, p. 38), aqui o autor nos fala sobre como percepcionamos às coisas ao nosso redor e que está ligado diretamente ao nosso repertório de vida. Assim, quando olhamos para o tecido automotivo ou para uma tira de cinto de segurança imediatamente fazemos uma conexão mental que ativa o nosso repertório de 
vida, e nos mostra já termos visto e entendido aquela imagem como "um tecido automotivo e um pedaço de cinto de segurança". Aqui temos um primeiro significado do material. Sem a nossa interferência este material será percebido sempre com o mesmo significado que lhe foi atribuído desde o momento do seu surgimento. Existem alguns materiais em nossa sociedade que já passaram por varias ressignificações ao longo do tempo como por exemplo, o tecido que surgiu com o objetivo único de cobrir nosso corpo, nos proteger, passando por mudanças signicas de acordo com a cultura local, onde em cada região do globo temos o tecido percebido de acordo com preceitos religiosos e culturais até chegar aos dias de hoje que demonstra claramente uma significação que perpassa pelo modismo e que faz indicações claras a que tribo (estrutura social) pertencemos.

Quando Rafaella Thomé, designer da cooperativa desde 2011, cria um novo produto utilizando esta matéria prima que já possui um significado em nossa sociedade, através do design, ela consegue manipular algumas variáveis, como: forma, composição, associação a outros elementos de modo a provocar no espectador uma nova forma de conceituar o objeto admirado, consequentemente a matéria prima ali utilizada. Neste momento a ressignificação do material acontece, ou seja, não o entendemos mais como uma tira de cinto de segurança, mas sim como um novo elemento, que também fará parte do nosso repertório de vida.

Vejamos o exemplo da Figura 3. Podemos observar a imagem de um artefato produzido pelo homem que faz parte do contexto feminino de nossa sociedade há muitos anos. Ao olharmos para este objeto a sua identificação é imediata, porque a imagem do objeto foi registrada em nossa mente várias vezes ao longo de nossas vidas. Porém, dificilmente identificaríamos a matéria prima aqui como sobras de cintos de segurança.

O mesmo acontece com as bolsas da Figura 4. Temos uma relação muito próxima com o artefato "bolsa", este objeto nos acompanha desde os primórdios da civilização humana e tem um papel cada vez mais inusitado, de acordo com o tempo e cultura local, como nos afirma Verganti: "A maneira que as pessoas dão significados aos produtos depende fortemente dos nossos valores, crenças, normas e tradições". (Verganti, 2012, p. 52)

Fazendo uma análise rápida da imagem na Figura 4 podemos notar que o estereótipo dos dois artefatos está intimamente relacionado ao que dentro do nosso repertório de vida conhecemos como bolsa feminina. Todos os elementos e acessórios empregados também fazem parte de outros objetos que são complemente similares, como: mochilas e malas de viagem. Esta associação, ao olharmos pela primeira vez para estes artefatos, nos leva a um arquivo memorial onde estão guardadas as referências e lembranças de outros objetos igualmente similares.

Mas a produção da Cooperárvore não se limita a estes artefatos. São produzidos uma variedade grande de produtos, todos utilizando a matéria prima de refugo da FIAT Automóveis e empresas fornecedoras para a mesma.

Entre os produtos estão: 1. Bandeja de pipoca; 2. Necessaire; 3. Porta celular; 4. Jogo de dama; 5. Sacola para carrinho de supermercado; 6. Jogo de gamão, que podem ser vistos na Figura 5. 


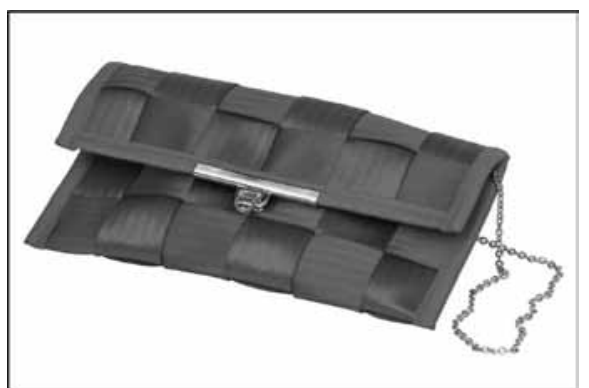

Figura 3.

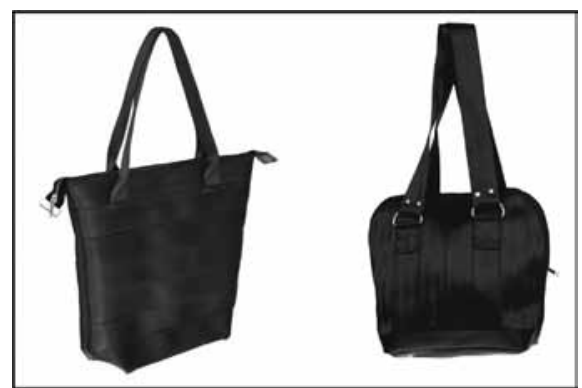

Figura 4.

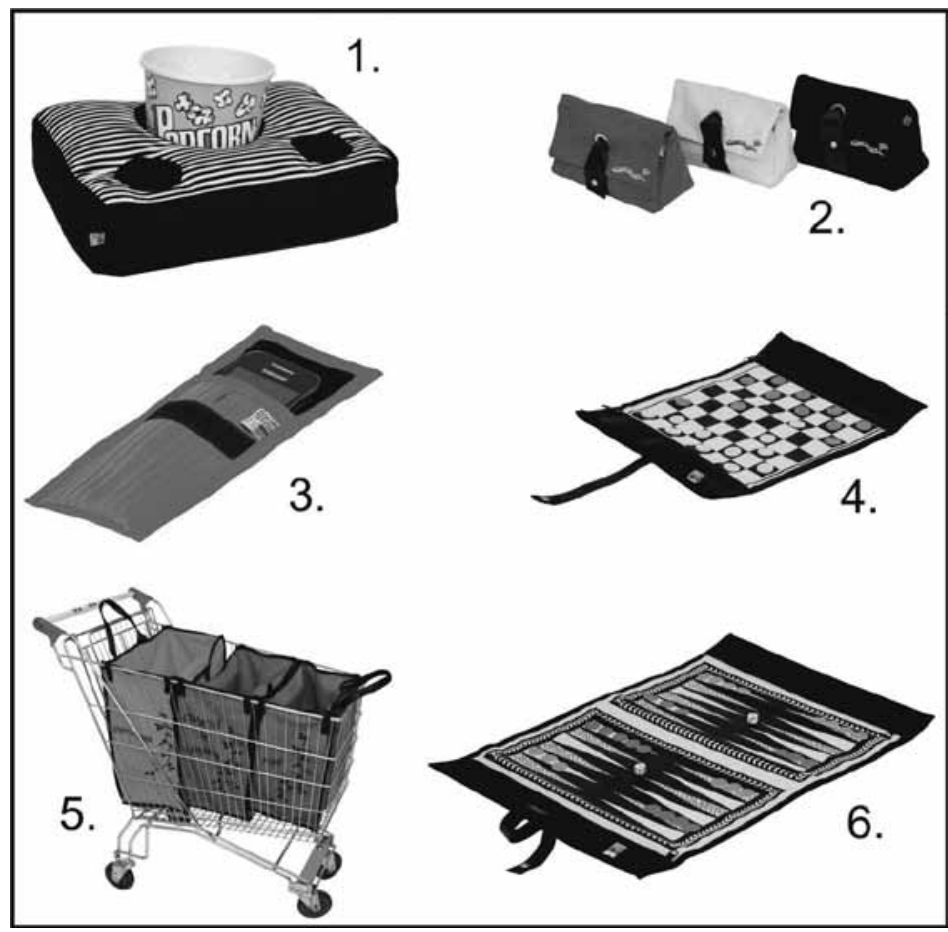

Figura 5.

Figura 3. Carteira Escarpas do Lago (Criação de produção da Cooperárvore). Fonte: Cooperárvore. Figura 4. Bolsa Mariana e Ouro Preto (Criação de produção da Cooperárvore). Fonte: Cooperárvore. Figura 5. Produtos desenvolvidos pela Cooperárvore. Fonte: Cooperárvore. 
Obsevando as imagens acima, podemos perceber claramente que se não falássemos sobre a matéria prima que deu origem a todos eles, dificilmente alguém as identificaria. A ressignificação de materiais é uma ferramenta importante para o design, que oferece a possibilidade de manipulação dos signos com o objetivo de favorecer uma situação socioeconômica de uma sociedade. Se imaginarmos a quantidade de materiais refugados dos mais variados segmentos das indústrias brasileiras, podemos entender a importância de se evitar que esta material se torne lixo. A ressignificação está diretamente relacionada com as questões de sustentabilidade que tanto aflige o mundo nos dias de hoje. Sua utilização de forma correta e consciente pode proporcionar um diferencial grande para milhares de pessoas e comunidades hoje em situação vulnerável socialmente. Jean Boudrillard nos apresenta um pensamento importante acerca disto:

O objeto-símbolo tradicional (os utensílios, os móveis, a própria casa), mediador de uma relação real ou de uma situação vivida, trazendo claramente impresso na sua substância e na sua forma a dinâmica consciente ou inconsciente desta relação, portanto não arbitrária, este objeto ligado, impregnado, pesado de conotação, mas sempre vivo por sua relação de interioridade, de transitividade em direção ao ato ou gesto humanos (coletivos ou individuais), este objeto não é consumido. Para torna-se objeto de consumo é preciso que o objeto se torne signo, quer dizer, exterior de alguma forma a relação da qual apenas significa, portanto arbitrário e não coerente com esta relação concreta, mas adquirindo coerência e sistemática com todos os outros objetos-signos. É então que ele se "personaliza", que entra em série, etc.: é consumido, jamais na sua materialidade, mas na sua diferença. (Baudrillard, 2006, p. 206)

\section{Considerações finais}

O lixo faz parte do cotidiano da raça humana e todos nós sabemos que a sua produção ainda é inevitável, mas grande parte destes materiais descartados, tanto por pessoas em suas residências quanto por empresas de diversos segmentos, podem encontrar novos aproveitamentos. Mas não se trata apenas de uma reutilização, porque o ser humano precisa sentir desejo pelo material ou produto reutilizado. Sabemos que alguns produtos oriundos da reciclagem nem sempre são aceitos em nossa sociedade como produtos geradores de valor, exatamente pelo fato de não provocarem em seus expectadores um valor a mais do que o seu de origem. Isto está ligado à forma como percebemos os objetos, a percepção determina o que nossos sentidos irão nos revelar e isto pode acontecer de forma completamente diferente de acordo com uma serie de variáveis, como situação, momento, lugar, condições e etc.

Os materiais e objetos passíveis de ressignificação precisam se tornar objetos de desejo.

Todo desejo é orientado a um objeto, seja ele uma coisa concreta ou uma idéia. Qualquer objeto pode ser analisado a partir das categorias forma X 
conteúdo ou forma X função. Entretanto, numa análise parcial se perde a relação indissociável entre essas duas categorias: forma não existe sem função; função não existe sem forma e as duas se constituem mutuamente. O problema de "funcionalizar" a forma é que leva à ilusão de que se pode controlar a função através da forma. $\mathrm{O}$ designer projeta uma forma para cumprir a função de satisfazer o desejo de outrem. Parte-se do princípio de que a função do objeto deve ser definida previamente pelo designer. Isso é ilusório porque o mais comum é as pessoas encontrarem funções para os objetos que seus designers nunca imaginaram!” (Amstel, 2007, p. 4)

São estes objetos de desejo que impulsionam nossa vontade de evoluir, de desenvolver, progredir, criando todas as condições necessárias para possuí-los. Neste momento, o trabalho de design associado à ressignifcação torna-se mais uma ferramenta forte e estratégica na busca por soluções de questões que afligem boa parte da sociedade contemporânea. Canclini (2008) acredita que todos os seres humanos relacionam-se com os objetos para satisfazer necessidades que são fixadas por nossa própria cultura, com a finalidade de nos integrarmos com outras pessoas e nos distinguirmos uns dos outros, para realizar nossos desejos e pensar em nossa situação no mundo. Aqui o autor nos fala da necessidade dos designers se colocarem no papel de consumidores, procurando vivenciar seus anseios, vontades e principalmente desejos. Só desta forma o design terá êxito ao ressignificar um artefato. Concluímos entendendo que o design tem também a função de significar ou ressignificar elementos, símbolos, valores, atributos, conceitos e usos às coisas que fazem parte do universo do ser humano. Com isto, ressignificar é dar um novo sentido/conceito ao objeto, alterando a forma como o percepcionamos ou o reinterpretamos.

\section{Referencias Bibliográficas}

Amstel, F. (21 maio 2007). A forma não segue necessariamente a função. Disponível em: $<\mathrm{http}$ ://usabilidoido.com.br/a_forma_nao_segue_nece ssariamente_a_funcao.html $>$. Acesso em: 19 jun. 2010.

Baudrillard, J. (2006). O sistema dos objetos. São Paulo: Perspectiva.

Belchior, C. (2011). Reciclando os sentidos: o papel do design na ressignificação dos objetos. Dissertação UEMG. Belo Horizonte, 2011. Disponível em: http://www.ppgd.uemg.br/ wp-content/uploads/2012/08/Camilo-de-Lelis-Belchior.pdf

Cardoso, R. (1998). "Design, cultura material e o fetichismo dos objetos". em Arcos: Design, Cultura Material e Visualidade (v. 1, pp. 14-39) Disponível em: www.esdi.uerj.br/ sobrearcos/artigos/artigo_rafael(14a39).pdf

Cardoso, R. (2013). Design para um mundo complexo. São Paulo: Cosac Naify.

García Canclini, N. (2008). Consumidores e cidadãos: conflitos multiculturais da globalização. Rio de Janeiro: UFRJ.

Grandesso, M. (2000). Sobre a reconstrução do significado: uma análise epistemológica e hermenêutica da prática clínica. São Paulo: Casa do Psicólogo.

Sudjic, D. (2010). A linguagem das coisas. Rio de Janeiro: Intrínseca. 
Thackara, J. (2008). Plano B: o design e as alternativas viáveis em um mundo complexo. São Paulo: Saraiva/Versar.

Verganti, R. (2012). Design-driven innovation: mudando as regras da competição. A inovação radical do significado de produtos. São Paulo: Canal Certo.

\begin{abstract}
This paper refers to an action that has been under development since 2006, with surprising results. Between a huge variety of automotive fabrics, remains of internal parts of cars (such as seatbelts, braces, etc.), in addition to a diversified machinery, 22 cooperatives work in Cooperárvore, a cooperative created by the FIAT's Community Engagement Program. This project is located in Betim $(\mathrm{BH})$. In a large warehouse belonging to this cooperative, a variety of products are created and generated from an innovative and ecologically correct raw material: inputs and cuts resulting from the internal production of the vehicles produced by FIAT.
\end{abstract}

Key words: social design - cooperative - sustainability - Corporate Social Responsibility.

Resumo: O presente artigo se refere a um estudo de caso sobre uma ação que já está sendo desenvolvida desde 2006, com resultado surpreendente. Entre uma variedade enorme de tecidos automotivos, retalhos de estruturas da parte interna dos carros, como cintos de segurança, alças e etc, além de um maquinário diversificado, 22 cooperadas trabalham na Cooperárvore, uma cooperativa criada pelo Programa de Política de Relacionamento com a comunidade de FIAT Automóveis. Este projeto está situado na cidade de Betim (BH). Em um grande galpão pertencente a esta cooperativa, são criados e produzidos uma variedade de produtos oriundos de uma matéria prima inovadora e ecologicamente correta, trata-se de insumos e aparas resultantes da produção interna dos veículos produzidos pela FIAT Automóveis.

Palavras chave: design social - cooperativa - sustentabilidade - Responsabilidade social corporativa. 